\title{
Clinical Characteristics of Patients with Spondyloarthritis in Japan in Comparison with Other Regions of the World
}

\author{
Mitsumasa Kishimoto, Kazuki Yoshida, Naomi Ichikawa, Hisashi Inoue, Yuko Kaneko, \\ Taku Kawasaki, Kazuo Matsui, Mitsuhiro Morita, Masei Suda, Kurisu Tada, Naoho Takizawa, \\ Naoto Tamura, Atsuo Taniguchi, Yoshinori Taniguchi, Shigeyoshi Tsuji, Yoichiro Haji, \\ Ryo Rokutanda, Haruyuki Yanaoka, Peter P. Cheung, Jieruo Gu, Tae-Hwan Kim (D, \\ Shue-Fen Luo, Masato Okada, Clementina López Medina, Anna Molto, Maxime Dougados, \\ Shigeto Kobayashi, Désirée van der Heijde, and Tetsuya Tomita
}

\begin{abstract}
Objective. To delineate clinical characteristics of patients with spondyloarthritis (SpA) in Japan in comparison to other areas of the world.

Methods. Using the ASAS-COMOSPA (Assessment of Spondyloarthritis international SocietyCOMOrbidities in SPondyloArthritis) data, an international cross-sectional observational study of patients with SpA, we analyzed information on demographics, disease characteristics, comorbidities, and risk factors. Patients were classified by region: Japan, other Asian countries (China, Singapore, South Korea, Taiwan), and non-Asian countries (Europe, the Americas, Africa). Patient characteristics, including diagnosis and treatment, were compared.

Results. Among 3984 patients included in the study, 161 were from centers in Japan, 933 from other Asian countries, and 2890 from other regions. Of patients with SpA in Japan, 42 (26.1\%) had peripheral SpA, substantially more than in other countries. This trend was explained by the predominance of psoriatic arthritis (PsA) among Japanese patients with SpA. In contrast to the relatively low number in Japan, $54 \%$ of patients from other Asian countries had pure axial SpA (axSpA) without peripheral features. HLA-B27 testing, considered an integral part of the classification of axSpA, was performed in only $63.6 \%$ of Japanese patients with axSpA. More than half of Japanese patients with axSpA were classified using imaging criteria.

Conclusion. In our study, there was a more substantial number of peripheral SpA cases observed in Japan compared to other parts of Asia and other regions of the world. Aside from ethnic differences, increasing recognition of PsA in Japan, as well as a potential underdiagnosis of axSpA due to the insufficient use of HLA-B27 testing, may partly explain regional discrepancies. (First Release February 15 2019; J Rheumatol 2019;46:896-903; doi:10.3899/jrheum.180412)
\end{abstract}

Key Indexing Terms:

AXIAL SPONDYLOARTHRITIS

PERIPHERAL SPONDYLOARTHRITIS

ANKYLOSING SPONDYLITIS

CLASSIFICATION CRITERIA

PSORIATIC ARTHRITIS

\begin{abstract}
From the Immuno-Rheumatology Center, St. Luke's International Hospital, St. Luke's International University; Institute of Rheumatology, Tokyo Women's Medical University; Department of Orthopedic Surgery, Juntendo University School of Medicine; Division of Rheumatology, Department of Rheumatology, Keio University School of Medicine, Tokyo; Department of Orthopedic Surgery, Shiga University of Medical Science, Shiga; Department of Rheumatology, Tonan Hospital, Hokkaido; Department of Orthopedic Surgery, Fujita Health University, Aichi; Department of Internal Medicine and Rheumatology, Juntendo University School of Medicine, Tokyo; Department of Rheumatology, Chubu Rosai Hospital, Aichi; Department of Endocrinology, Metabolism and Nephrology, Kochi Medical School, Kochi; Department of Orthopedics, Osaka Minami Medical Center, Osaka; Department of Rheumatology, Daido Hospital, Aichi; Department of Internal Medicine, Juntendo University Koshigaya Hospital, Saitama; Department of Orthopedic Biomaterial Science, Osaka University Graduate School of Medicine, Osaka, Japan; departments of Epidemiology and Biostatistics, Harvard T.H. Chan School of Public Health, Boston, Massachusetts, USA; Division of Rheumatology, National University Hospital, Singapore; Division of
\end{abstract}

\begin{abstract}
Rheumatology, The Third Affiliated Hospital of Sun Yat-sen University, Guangzhou, China; Department of Rheumatology, Hanyang University Hospital for Rheumatic Diseases, Seoul, South Korea; Department of Rheumatology, Allergy and Immunology, Chang Gung Memorial Hospital and Chang Gung University, Tao-Yuan, Taiwan; Hospital Universitario Reina Sofía/IMIBIC/University of Córdoba, Córdoba, Spain; Department of Rheumatology, Paris Descartes University, Cochin Hospital, Paris, France; INSERM Unit 1183, CRESS, Paris, France; Department of Rheumatology, Leiden University Medical Center, Leiden, the Netherlands.
\end{abstract}

This study was conducted under the umbrella of the International Society for Spondyloarthritis Assessment (ASAS) and the COMOSPA study was supported by the unrestricted grants from Pfizer, AbbVie, and UCB. M.K. received honoraria from AbbVie and Ayumi; K.Y. receives tuition support from Harvard T.H. Chan School of Public Health (partially supported by training grants from Pfizer, Takeda, Bayer, and PhRMA); A.M. has received research grants from Abbvie, Pfizer, and MSD. M. Kishimoto, MD, Immuno-Rheumatology Center, St. Luke's 
Spondyloarthritis $(\mathrm{SpA})$ is considered relatively rare in Japan, where the HLA-B27 positivity rate is $<0.3 \%$, with an estimated incidence rate of $0.48 / 100,000$ persons per year and an estimated population prevalence of $<0.01 \%{ }^{1,2}$. However, in daily practice, $\mathrm{SpA}$ is increasingly diagnosed, a trend correlating with recent awareness of this disease entity; this suggests a potentially severe underdiagnosis in the previous time periods. Further improvement of disease awareness is necessary to allow patients to receive appropriate treatments.

Another potential problem is the misdiagnosis of $\mathrm{SpA}$ as rheumatoid arthritis (RA) or other joint conditions. Awareness of clinical characteristics of SpA, including both articular and extraarticular manifestations, is essential for recognizing axial and peripheral SpA. Clinical characteristics of SpA are highly variable across patients, and may vary across patient populations, particularly because of differing distributions of HLA and other genetic factors.

In this study, we aim to characterize the distinguishing

International Hospital, St. Luke's International University; K. Yoshida, $M D, M P H, S c D$, Departments of Epidemiology and Biostatistics, Harvard T.H. Chan School of Public Health; N. Ichikawa, MD, Institute of Rheumatology, Tokyo Women's Medical University; H. Inoue, MD, Department of Orthopedic Surgery, Juntendo University School of Medicine; Y. Kaneko, MD, Division of Rheumatology, Department of Rheumatology, Keio University School of Medicine; T. Kawasaki, MD, Department of Orthopedic Surgery, Shiga University of Medical Science; K. Matsui, MD, Department of Rheumatology, Tonan Hospital, M. Morita, $M D$, Department of Orthopedic Surgery, Fujita Health University; M. Suda, MD, Immuno-Rheumatology Center, St. Luke's International Hospital, St. Luke's International University; K. Tada, MD, Department of Internal Medicine and Rheumatology, Juntendo University School of Medicine; N. Takizawa, MD, Department of Rheumatology, Chubu Rosai Hospital; N. Tamura, MD, Department of Internal Medicine and Rheumatology, Juntendo University School of Medicine; A. Taniguchi, $M D$, Institute of Rheumatology, Tokyo Women's Medical University; Y. Taniguchi, MD, Department of Endocrinology, Metabolism and Nephrology, Kochi Medical School; S. Tsuji, MD, Department of Orthopedics, Osaka Minami Medical Center; Y. Haji, MD, Department of Rheumatology, Daido Hospital; R. Rokutanda, MD, ImmunoRheumatology Center, St. Luke's International Hospital, St. Luke's International University; H. Yanaoka, MD, Immuno-Rheumatology Center, St. Luke's International Hospital, St. Luke's International University; P.P. Cheung, MD, Division of Rheumatology, National University Hospital; J. Gu, MD, Division of Rheumatology, The Third Affiliated Hospital of Sun Yat-sen University; T.H. Kim, MD, Department of Rheumatology, Hanyang University Hospital for Rheumatic Diseases; S.F. Luo, MD, Department of Rheumatology, Allergy and Immunology, Chang Gung Memorial Hospital and Chang Gung University; M. Okada, MD, Immuno-Rheumatology Center, St. Luke's International Hospital, St.

Luke's International University; C. López Medina, MD, Hospital

Universitario Reina Sofía/IMIBIC/University of Córdoba; A. Molto, MD,

Department of Rheumatology, Paris Descartes University, Cochin Hospital, and INSERM Unit 1183, CRESS; M. Dougados, MD,

Department of Rheumatology, Paris Descartes University, Cochin Hospital, and INSERM Unit 1183, CRESS; S. Kobayashi, MD, PhD, Department of Internal Medicine, Juntendo University Koshigaya Hospital; D. van der Heijde, MD, Department of Rheumatology, Leiden University Medical Center; T. Tomita, MD, Department of Orthopedic Biomaterial Science, Osaka University Graduate School of Medicine.

Address correspondence to Dr. M. Kishimoto, Immuno-Rheumatology

Center, St. Luke's International Hospital, St. Luke's International

University, 9-1 Akashicho, Chuo-ku, Tokyo, Japan, 104-8560.

E-mail: kishimotomi@gmail.com

Accepted for publication October 11, 2018. clinical features of SpA in Japanese patients, which should then allow us to avoid both underdiagnosis and misdiagnosis of this increasingly treatable disease entity.

\section{MATERIALS AND METHODS}

Study population and design. We used data from the Assessment in SpondyloArthritis international Society-COMOrbidities in SPondyloArthritis (ASAS-COMOSPA) study, an international multicenter crosssectional observational study with 22 participating countries from 4 continents (Africa, the Americas, Asia, and Europe). The initial aim of the study was to describe the prevalence of various comorbidities among patients with SpA. The details of the study have been previously described ${ }^{3}$. Briefly, the ASAS-COMOSPA appointed a scientific committee, which selected national principal investigators from participating countries. Each principal investigator was asked to invite rheumatologists in their country to ensure appropriate patient representation.

Consecutive patients aged $\geq 18$ years and fulfilling the ASAS criteria (either axial or peripheral $)^{4}$, and who were capable of understanding and completing questionnaires, were enrolled. Hôpital Cochin, APHP institutional review board approved the ASAS-COMOSPA study protocol (\#SC 3004) and approval was also obtained for each study site (22 countries); the study was conducted according to guidelines for good clinical practice in all countries. Written informed consent was obtained from all subjects before enrollment.

Patient characteristic assessment. Patients' information was collected by a study investigator or a research nurse during a face-to-face patient interview at each study site. Patients' medical records were also examined for further information. The information collected was classified into 4 domains: demographics and disease characteristics, comorbidities, risk factors for comorbidities, and adherence with recommendations for monitoring of comorbidities. Because our aim was to examine disease characteristics across different countries, we mainly used the demographics and disease characteristics data.

Demographic data included age, sex, body mass index (BMI), smoking status, alcohol intake, the highest level of education completed, and marital status. Disease characteristics included axial involvement, peripheral SpA features (e.g., peripheral arthritis, enthesitis, and dactylitis), and extraarticular manifestations [e.g., inflammatory bowel disease (IBD), uveitis, psoriasis]. SpA disease activity was measured by the Bath Ankylosing Spondylitis Disease Activity Index (BASDAI) ${ }^{5}$, the Ankylosing Spondylitis Disease Activity Score calculated with C-reactive protein (CRP; $\mathrm{mg} / \mathrm{l}^{6,7}$ and the number of swollen joints (44 joints). SpA disease severity was assessed by the history of surgeries related to $\mathrm{SpA}$, the presence of a bamboo spine, and the Bath Ankylosing Spondylitis Functional Index (BASFI) ${ }^{8}$. Past and current medications [nonsteroidal antiinflammatory drugs (NSAID), glucocorticoids, conventional synthetic (cs) and biologic (b) disease-modifying antirheumatic drugs (DMARD)] were also examined.

Patient group definition. Because our primary outcome of interest was differences in the distribution of clinical characteristics of patients with SpA across countries, we grouped patients based on their country of origin: Japan, other Asian countries (China, Singapore, South Korea, and Taiwan), and non-Asian countries (Europe, the Americas, and Africa). We classified patients into the ASAS axial SpA (axSpA) subgroup if they met the ASAS axSpA criteria ${ }^{4}$ : (1) imaging arm [i.e., sacroiliitis on magnetic resonance imaging (MRI) or radiographs ${ }^{9}$ ] plus $\geq 1$ clinical characteristics of $\mathrm{SpA}$; or (2) clinical arm (i.e., HLA-B27 positivity plus $\geq 2$ clinical characteristics of $\mathrm{SpA}$ ). Patients were classified into the ASAS peripheral SpA subgroup if they did not meet the axial criteria and had a physician diagnosis of peripheral arthritis, enthesitis, or dactylitis and $\mathrm{SpA}$ clinical characteristics ( $\geq 1$ specific findings or $\geq 2$ less specific findings $)^{4,10}$. We made regional comparisons for patients overall, as well as within each of the ASAS axSpA and peripheral SpA subgroups. Classification of psoriatic arthritis (PsA) was based on the ClASsification for Psoriatic ARthritis criteria (CASPAR) criteria ${ }^{11}$. 
Statistical analyses. Descriptive statistics of patient demographics and disease characteristics, activity, and severity of SpA were provided in the Japanese subgroup, comparing with those in the rest of the Asian countries and non-Asian countries. Prevalence of characteristics was compared across regions using ANOVA (continuous variables) or chi-square test (categorical variables) to identify clinical features that were more characteristic of Japanese patients with SpA. All analyses were conducted using R version 3.4 .2 (www.r-project.org), using the tableone package for tables ${ }^{12}$ and the VennDiagram package for figures ${ }^{13}$.

\section{RESULTS}

Study population and clinical characteristics of patients. Among 3984 patients included in the study, 161 were from centers in Japan, 933 from other Asian countries (China, Singapore, South Korea, and Taiwan), and 2890 from North and South America, Europe, or Africa. The overall patient characteristics in different regions are summarized in Table 1. Japanese SpA patients were older at the time of diagnosis compared to patients in other areas. The average time between disease onset to diagnosis was 10 years in Japan, whereas it was 4 years in other Asian patients and 8 years in other regions. The proportion of female patients was 33.5\% in Japan versus $39.3 \%$ in non-Asian areas, and was lower at $22.1 \%$ in other Asian countries.

Table 1. Characteristics of all included patients across regions.

\begin{tabular}{|c|c|c|c|c|}
\hline Variables & Japan & Asia & Non-Asia & $\mathrm{p}$ \\
\hline $\mathrm{N}$ & 161 & 933 & 2890 & \\
\hline Age at enrollment, yrs, mean (SD) & $48.9(14.5)$ & $37.0(12.9)$ & $45.5(13.5)$ & $<0.001$ \\
\hline Age at disease diagnosis, yrs, mean (SD) & $42.0(15.7)$ & $30.9(11.9)$ & $36.5(12.6)$ & $<0.001$ \\
\hline Female & $54(33.5)$ & $206(22.1)$ & $1134(39.3)$ & $<0.001$ \\
\hline Smoking status & & & & $<0.001$ \\
\hline Current & $36(22.5)$ & $234(25.1)$ & $644(22.3)$ & \\
\hline BMI, mean (SD) & $23.8(4.0)$ & $23.6(4.6)$ & $27.1(5.8)$ & $<0.001$ \\
\hline Obese & $9(5.6)$ & $74(8.0)$ & $680(24.0)$ & $<0.001$ \\
\hline ASAS SpA classification & & & & $<0.001$ \\
\hline Axial (radiograph+) & $66(41.0)$ & $602(64.5)$ & $1511(52.3)$ & \\
\hline Axial (radiograph-) & $11(6.8)$ & $101(10.8)$ & $486(16.8)$ & \\
\hline Peripheral arthritis & $120(74.5)$ & $428(45.9)$ & $1831(63.4)$ & $<0.001$ \\
\hline Enthesitis & $77(47.8)$ & $217(23.3)$ & $1212(41.9)$ & $<0.001$ \\
\hline Dactylitis & $43(26.7)$ & $67(7.2)$ & $508(17.6)$ & $<0.001$ \\
\hline Psoriasis & $66(41.0)$ & $68(7.3)$ & $805(27.9)$ & $<0.001$ \\
\hline CASPAR criteria & $67(41.6)$ & $61(6.5)$ & $766(26.5)$ & $<0.001$ \\
\hline HLA-B27 measured & $80(49.7)$ & $839(89.9)$ & $2142(74.1)$ & $<0.001$ \\
\hline HLA-B27 positivity among measured & $47(58.8)$ & $740(88.2)$ & $1430(66.8)$ & $<0.001$ \\
\hline $\mathrm{ESR}, \mathrm{mm} / \mathrm{h}$, mean $(\mathrm{SD})$ & $18.6(19.5)$ & $19.7(20.4)$ & $18.8(19.6)$ & 0.505 \\
\hline $\mathrm{CRP}$ & $0.3(0.1,1.1)$ & $0.7(0.3,2.7)$ & $0.7(0.3,2.9)$ & $<0.001$ \\
\hline $\mathrm{PGA}(0-10)$ & $1.0(1.0,3.0)$ & $3.0(2.0,5.0)$ & $3.0(2.0,5.0)$ & $<0.001$ \\
\hline $\operatorname{PtGA}(0-10)$ & $3.0(1.0,5.0)$ & $4.0(2.0,6.0)$ & $4.0(2.0,6.0)$ & $<0.001$ \\
\hline BASFI & $0.8(0.0,2.7)$ & $1.0(0.2,2.8)$ & $3.0(1.1,5.6)$ & $<0.001$ \\
\hline Ischemic heart disease or stroke & $5(3.1)$ & $16(1.7)$ & $120(4.2)$ & 0.002 \\
\hline Vertebral or fragility fractures & $11(6.8)$ & $33(3.5)$ & $147(5.1)$ & 0.073 \\
\hline
\end{tabular}

Values are expressed as $\mathrm{n}(\%)$ or median (IQR) unless otherwise indicated. BMI: body mass index; ASAS: Assessment of Spondyloarthritis international Society; SpA: spondyloarthritis; CASPAR: ClASsification for Psoriatic ARthritis; ESR: erythrocyte sedimentation rate; CRP: C-reactive protein; PGA: physician's global assessment; PtGA: patient's global assessment; BASFI: Bath Ankylosing Spondylitis Functional Index; BASDAI: Bath Ankylosing Spondylitis Disease Activity Index; NSAID: nonsteroidal antiinflammatory drug; DMARD: disease-modifying antirheumatic drug. 
A striking difference was found in the composition of SpA. Among Japanese SpA patients, 26.1\% presented peripheral SpA without axial symptoms. The corresponding proportion was only $7.2 \%$ in other Asian countries and $15.5 \%$ in non-Asian regions (Table 1). Patients with pure axSpA without peripheral features constituted only $11.2 \%$ of patients in Japan, whereas it was greater $(40.4 \%)$ in other Asian countries. The other countries were intermediate, with $24.1 \%$ of patients falling into the pure axSpA category.

The proportion of patients with inflammatory back pain, CRP level, physician's global assessment score, patient's global assessment score, BASFI, BASDAI, and NSAID use were all lower in Japanese patients compared to patients in other regions. Glucocorticoid use was seen in about $10 \%$ of patients regardless of the region. Use of csDMARD, including methotrexate, leflunomide, hydroxychloroquine, gold salts, azathioprine, and sulfasalazine was similar between Japanese patients (62.7\%) and non-Asian patients (63.5\%), but slightly lower in other Asian patients (52.5\%), which may be explained by the axial-dominant composition of those patients. The use of bDMARD was similar between Japanese patients (31.7\%) and other Asian patients (28.6\%) but was substantially higher in other countries (49.8\%). The comorbidity profile of Japanese patients with SpA was more similar to those in non-Asian countries.

ASAS axSpA subgroup. Among the patients, 77 Japanese patients (47.8\%), 703 other Asian patients (75.3\%), and 1997 non-Asian patients (69.1\%) met ASAS axSpA criteria. In the axSpA subset (Table 2), the age of onset was relatively similar across regions (24.2 yrs in Japan, $24.7 \mathrm{yrs}$ in other Asian countries, and $27.1 \mathrm{yrs}$ in non-Asian regions). The diagnosis was again most delayed in Japan (10 yrs) compared to other regions ( $5 \mathrm{yrs}$ in other Asian countries, $7 \mathrm{yrs}$ in non-Asian areas). The proportions of patients with inflammatory back pain were similar across regions: $96.1 \%$ in Japan, $97.2 \%$ in other Asia, and $98.8 \%$ in other regions. When we examined how these patients were classified as having ASAS axSpA, we found different patterns across regions (Figure 1). In other Asian countries, $73.0 \%$ of patients met both imaging and clinical (HLA-B27-based) arms of the ASAS criteria; this proportion was lower in Japan (49.4\%) and other regions (51.8\%). The proportion of patients who received HLA-B27 testing was only $63.6 \%$ in Japan, compared to $92.9 \%$ in other Asian countries, and $83.5 \%$ in other regions (Table 2). However, among those who were tested, positive results were found in $79.6 \%$ of patients in Japan, compared to $93.1 \%$ in other Asian countries, and $72.6 \%$ in other regions. Around half of SpA patients in Japan were classified according to imaging arm only, although the proportions of patients with positive sacroiliitis on radiograph were similar between Japanese patients (85.7\%) and other Asian patients (85.6\%) and was higher than other regions (75.7\%). The proportions of patients classified as axSpA with peripheral features (arthritis, enthesitis, or dactylitis) were
$76.6 \%$ in Japan, $46.4 \%$ in other Asian countries, and $65.1 \%$ in other regions. Peripheral arthritis was most common in Japanese patients with axSpA (62.3\%), followed by patients in other countries (53.1\%) and other Asian patients (40.1\%). For extraarticular manifestations, the proportions with psoriasis (16.9\%) and IBD (7.8\%) among Japanese patients were more similar to the non-Asian countries (psoriasis $17.0 \%$ and IBD 6.7\%) than other Asian countries (psoriasis $4.7 \%$ and IBD $1.6 \%$ ).

ASAS peripheral SpA subgroup. Forty-two Japanese patients (26.1\%), 67 other Asian patients (7.2\%), and 449 patients from other regions (15.5\%) met the criteria for ASAS peripheral SpA (Table 3). The age of onset in this subgroup was several years older in Japanese patients (38.3 yrs) compared to the other 2 groups (30.0 yrs in other Asian countries and $33.4 \mathrm{yrs}$ in other regions). The mean time to diagnosis was close to 10 years in Japan and other regions but was shorter $(<5$ yrs $)$ in other Asian countries. Interestingly, Japanese patients with peripheral SpA had a similar mean BMI to axSpA patients, whereas peripheral SpA patients were more overweight or obese in the other 2 regions. Psoriatic skin lesions were most common in Japanese patients (71.4\%), followed by other regions (61.2\%) and other Asian countries (23.9\%). HLA-B27 testing was less frequent among these patients than among patients with axSpA (38.1\% in Japan, $88.1 \%$ in other Asia, and $55.9 \%$ in other countries). Among those who had HLA-B27 testing, positivity was seen in $31.2 \%$ in Japan, $74.6 \%$ in other Asian countries, and $53.0 \%$ in other countries. Swollen joint counts and erythrocyte sedimentation rates were similar across 3 groups. However, CRP was lower in Japanese patients $(0.20$ $\mathrm{mg} / \mathrm{dl})$ compared to other Asian patients $(0.50 \mathrm{mg} / \mathrm{dl})$ or patients in other regions $(0.70 \mathrm{mg} / \mathrm{dl})$. The most common mode of treatment in Japanese patients was csDMARD (78.6\%), which was more common than NSAID (71.4\%). NSAID use was more common in other Asian patients $(91.0 \%)$ and patients in other regions $(87.1 \%)$, although csDMARD use showed smaller regional differences $(70.1 \%$ in other Asia and $80.6 \%$ in other regions).

\section{DISCUSSION}

In our study, we examined the clinical characteristics of Japanese patients with SpA in comparison to patients in other Asian countries as well as other regions, to clarify the differences in the composition, clinical features, and practice patterns. While a recent analysis of ASAS-COMOSPA data confirmed substantial overlap between classification criteria sets, a detailed study of Japanese patients in relation to other populations was not performed ${ }^{14}$. We found striking differences in patients having peripheral SpA in Japan $(26.1 \%$ in Japan, $7.2 \%$ in other Asian countries, and $15.5 \%$ in other countries) compared to other regions, in which axSpA is more prevalent. Upon further examination, this seemed to be due to the predominance of psoriasis among Japanese patients,

$$
\text { Personal non-commercial use only. The Journal of Rheumatology Copyright (c) 2019. All rights reserved. }
$$


Table 2. Characteristics of ASAS axial SpA patients across regions.

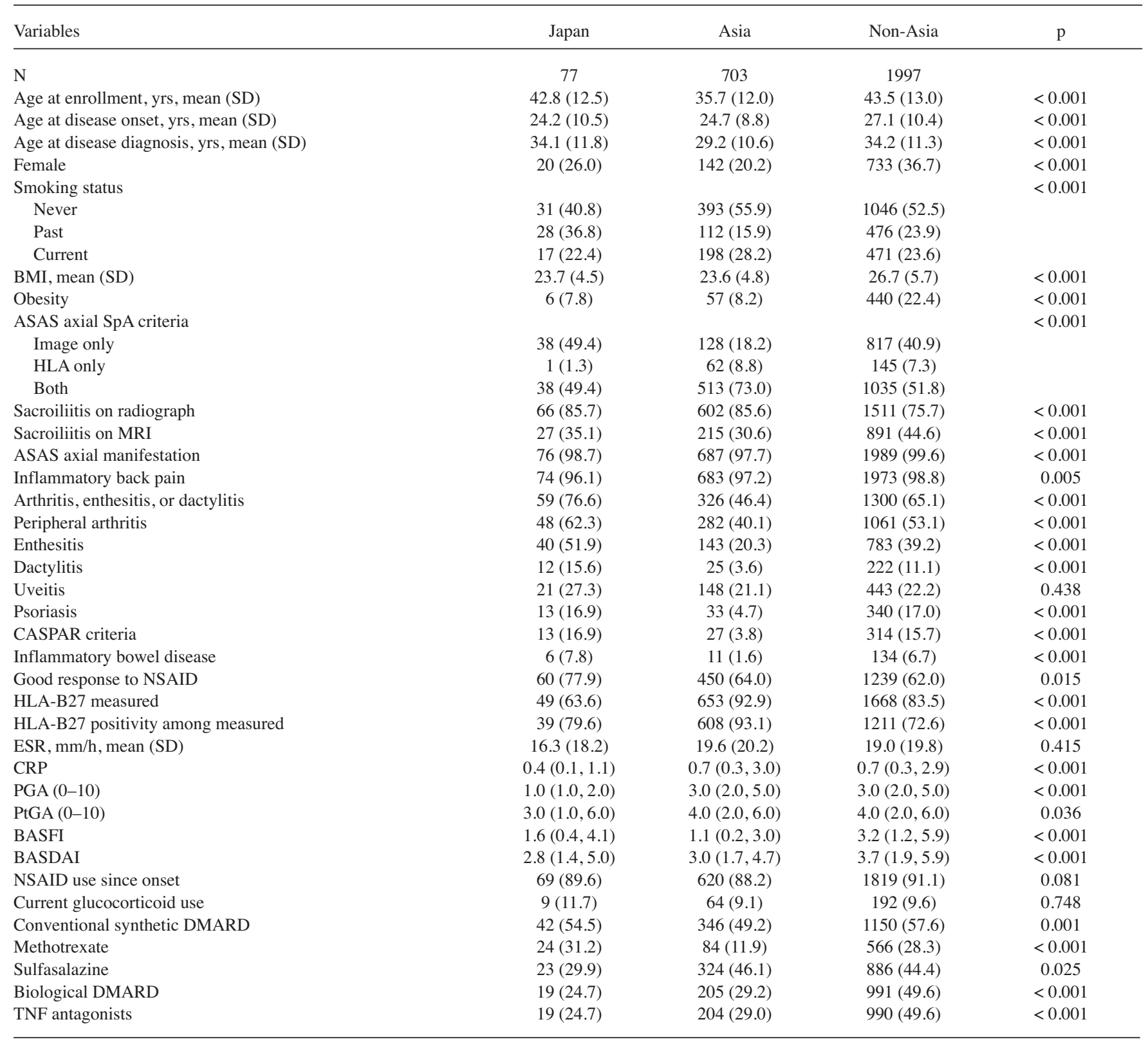

Values are expressed as n (\%) or median (IQR) unless otherwise indicated. BMI: body mass index; ASAS: Assessment of Spondyloarthritis international Society; SpA: spondyloarthritis; MRI: magnetic resonance imaging; CASPAR: ClASsification for Psoriatic ARthritis; ESR: erythrocyte sedimentation rate; CRP: C-reactive protein; PGA: physician's global assessment; PtGA: patient's global assessment; BASFI: Bath Ankylosing Spondylitis Functional Index; BASDAI: Bath Ankylosing Spondylitis Disease Activity Index; NSAID: nonsteroidal antiinflammatory drug; DMARD: disease-modifying antirheumatic drug; TNF: tumor necrosis factor.

regardless of axial or peripheral disease. This is in contrast to $40.4 \%$ of patients reported from other Asian countries (China, Singapore, South Korea, and Taiwan) having pure axSpA without meeting the peripheral features. Our study is a cross-sectional study including consecutive patients seen at the participating rheumatology departments. However, it is unknown whether truly consecutive patients were included in the study. This may have influenced the prevalence of various characteristics to some extent. However, it is unlikely that this explains all the differences seen, and our data present an overview of patients seen at the various rheumatology departments in various regions.

A previous study reports an HLA-B27 positivity rate of $<0.3 \%$ in the general Japanese population, compared to rates of about $5-10 \%$ in other Asian and non-Asian countries ${ }^{1,15}$. This substantially lower prevalence appears to be an ethnic

Personal non-commercial use only. The Journal of Rheumatology Copyright $@$ (0) 2019. All rights reserved. 


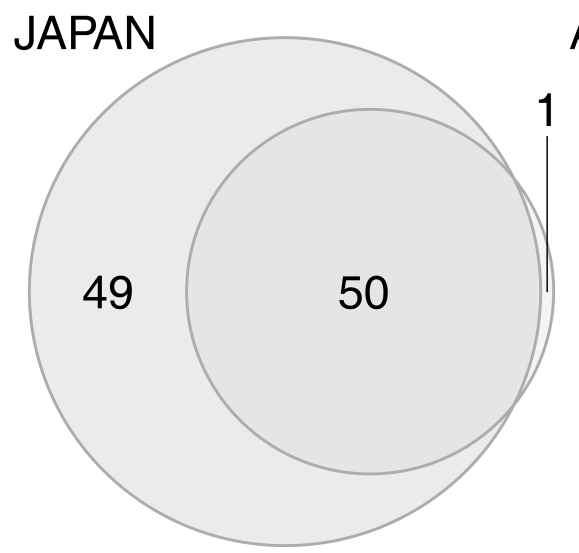

ASIA

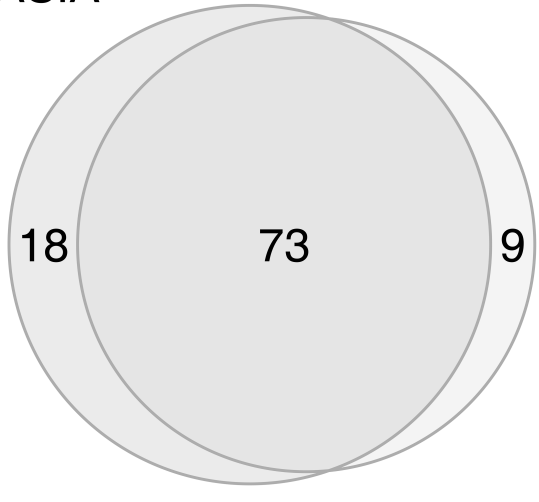

OTHERS

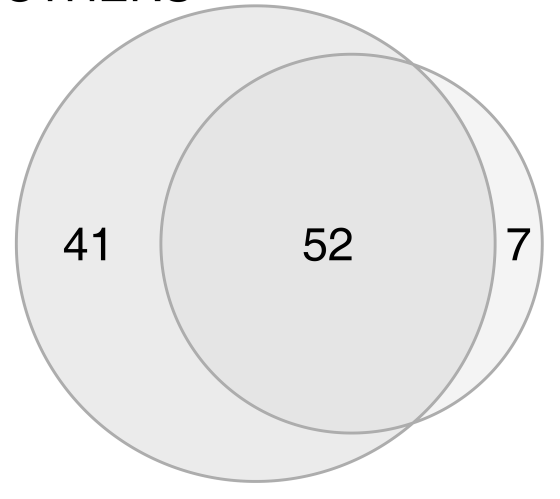

Figure 1. The proportions of patients meeting the imaging, clinical, or both arms of ASAS criteria among patients with axSpA. The left circle in each panel represents those who met the ASAS imaging arm of the ASAS criteria for axSpA (imaging evidence of sacroiliitis and $\geq 1$ clinical features), and the right circle represents those who met the ASAS clinical arm of the ASAS criteria for axSpA (positive HLA-B27 and $\geq 2$ clinical features). ASAS: Assessment of Spondyloarthritis international Society; axSpA: axial spondyloarthritis.

Table 3. Characteristics of ASAS peripheral SpA patients across regions.

\begin{tabular}{|c|c|c|c|c|}
\hline Variables & Japan & Asia & Non-Asia & $\mathrm{p}$ \\
\hline $\mathrm{N}$ & 42 & 67 & 449 & \\
\hline Age at enrollment, yrs, mean (SD) & $53.3(14.6)$ & $38.8(14.2)$ & $50.2(13.7)$ & $<0.001$ \\
\hline Age at disease diagnosis, yrs, mean (SD) & $47.8(15.0)$ & $34.9(13.8)$ & $41.5(13.9)$ & $<0.001$ \\
\hline Female & $14(33.3)$ & $19(28.4)$ & $209(46.5)$ & 0.008 \\
\hline Smoking status & & & & 0.001 \\
\hline Current & $10(23.8)$ & $9(13.4)$ & $71(15.8)$ & \\
\hline BMI, mean (SD) & $23.7(3.5)$ & $24.2(4.2)$ & $28.4(6.2)$ & $<0.001$ \\
\hline Obesity & $1(2.4)$ & $7(10.4)$ & $144(33.1)$ & $<0.001$ \\
\hline Peripheral arthritis & $42(100.0)$ & $64(95.5)$ & $424(94.4)$ & 0.280 \\
\hline Enthesitis & $20(47.6)$ & $35(52.2)$ & $223(49.7)$ & 0.886 \\
\hline Dactylitis & $20(47.6)$ & $20(29.9)$ & $171(38.1)$ & 0.171 \\
\hline Good response to NSAID & $18(42.9)$ & $48(71.6)$ & $245(54.6)$ & 0.007 \\
\hline HLA-B27 measured & $16(38.1)$ & $59(88.1)$ & $251(55.9)$ & $<0.001$ \\
\hline HLA-B27 positivity among measured & $5(31.2)$ & $44(74.6)$ & $133(53.0)$ & 0.001 \\
\hline Swollen joint count $(0-44)$ & $1.0(0.0,2.0)$ & $1.0(0.0,2.0)$ & $1.0(0.0,2.0)$ & 0.603 \\
\hline Tender joint count $(0-44)$ & $1.0(0.0,2.0)$ & $1.0(0.0,2.0)$ & $2.0(0.0,4.0)$ & 0.007 \\
\hline $\mathrm{ESR}, \mathrm{mm} / \mathrm{h}$, mean $(\mathrm{SD})$ & $21.8(22.1)$ & $26.8(28.0)$ & $20.6(20.2)$ & 0.114 \\
\hline CRP & $0.2(0.1,1.3)$ & $0.5(0.3,1.6)$ & $0.7(0.3,2.6)$ & 0.011 \\
\hline $\operatorname{PGA}(0-10)$ & $2.0(1.0,3.0)$ & $4.0(2.0,4.0)$ & $3.0(2.0,5.0)$ & 0.001 \\
\hline $\operatorname{PtGA}(0-10)$ & $1.0(1.0,3.0)$ & $3.0(2.0,7.0)$ & $4.0(2.0,6.0)$ & $<0.001$ \\
\hline NSAID use since onset & $30(71.4)$ & $61(91.0)$ & $391(87.1)$ & 0.009 \\
\hline Current glucocorticoid use & $2(4.8)$ & $18(26.9)$ & $81(18.0)$ & 0.014 \\
\hline Conventional synthetic DMARD & $33(78.6)$ & $47(70.1)$ & $362(80.6)$ & 0.143 \\
\hline
\end{tabular}

Values are expressed as n (\%) or median (IQR) unless otherwise indicated. BMI: body mass index; ASAS: Assessment of Spondyloarthritis international Society; SpA: spondyloarthritis; CASPAR: ClASsification for Psoriatic ARthritis; ESR: erythrocyte sedimentation rate; CRP: C-reactive protein; PGA: physician's global assessment; PtGA: patient's global assessment; BASFI: Bath Ankylosing Spondylitis Functional Index; BASDAI: Bath Ankylosing Spondylitis Disease Activity Index; NSAID: nonsteroidal antiinflammatory drug; DMARD: disease-modifying antirheumatic drug; TNF: tumor necrosis factor.

Personal non-commercial use only. The Journal of Rheumatology Copyright $\subset$ 2019. All rights reserved. 
characteristic of the Japanese population, also influencing the observed HLA-B27 rate in the Japanese patients with SpA. Further to this, we found markedly lower rates of HLA measurement in the Japanese health services context. HLA-B27 testing is considered an integral part of the diagnosis of axSpA but is not reimbursed under current Japanese insurance schemes; it was performed in only $63.6 \%$ of Japanese patients with axSpA. Therefore around half of Japanese patients with axSpA were classified based on the imaging arm of the ASAS criteria alone. A previous study from Denmark suggested a high false-positive rate of sacroiliitis (21\%) on MRI in patients with persistent low back pain $^{16}$. Though classification criteria and diagnosis should not be conflated, differences in classification modalities as well as different rates of HLA-B27 testing between countries may also contribute to the 10-year gap between onset and diagnosis that is consistently seen among patients with SpA in Japan, and which is substantially more than in other countries. AxSpA is still considered by many Japanese rheumatologists to be a typically male disease, and an atypical presentation in, for example, women may contribute to delayed diagnosis in Japan. Ongoing research supported by the Japanese Ministry of Health aims to better characterize the epidemiology of SpA in Japan and to develop a guideline for diagnosis and treatment.

In Japan, PsA among patients with SpA remains strikingly common, whereas pure axSpA is more common in other Asian countries and non-Asian regions. Further, the more common prevalence of axSpA versus RA in China ${ }^{17,18}$ as well as the high prevalence of HLA-B27 positivity in this study both likely contribute to the high prevalence of pure axSpA in China. On the other hand, the prevalence of PsA among patients with psoriasis has been considered lower in Asian countries compared to non-Asian countries 19,20,21,22,23. However, we previously showed that the prevalence of PsA among patients with psoriasis might be as high as $20 \%$, similar to that in Western countries ${ }^{24}$. Because awareness of PsA is increasing, partly because of the advent of effective new treatments such as biological agents, PsA prevalence has recently been found to be markedly higher, from $1 \%$ to $10 \%$, in patients with psoriasis ${ }^{25}$. We hope that increased awareness of axSpA in Japan will result in a similar trend.

Japanese patients with SpA demonstrated unique clinical features compared to other Asian and non-Asian countries. The relatively common presence of psoriasis should be recognized to further facilitate early diagnosis and treatment. These results offer an opportunity to improve both early diagnosis and treatment of patients with SpA in Japan.

\section{REFERENCES}

1. Ikeda N, Kojima H, Nishikawa M, Hayashi K, Futagami T, Tsujino T, et al. Determination of HLA-A, -C, -B, -DRB1 allele and haplotype frequency in Japanese population based on family study. Tissue Antigens 2015;85:252-9.

2. Hukuda S, Minami M, Saito T, Mitsui H, Matsui N, Komatsubara Y, et al. Spondyloarthropathies in Japan: nationwide questionnaire survey performed by the Japan Ankylosing Spondylitis Society. J Rheumatol 2001;28:554-9.

3. Moltó A, Etcheto A, van der Heijde D, Landewé R, van den Bosch F, Bautista Molano W, et al. Prevalence of comorbidities and evaluation of their screening in spondyloarthritis: results of the international cross-sectional ASAS-COMOSPA study. Ann Rheum Dis 2016;75:1016-23.

4. Rudwaleit M, van der Heijde D, Landewé R, Listing J, Akkoc N, Brandt J, et al. The development of Assessment of SpondyloArthritis international Society classification criteria for axial spondyloarthritis (part II): validation and final selection. Ann Rheum Dis 2009;68:777-83.

5. Garrett S, Jenkinson T, Kennedy LG, Whitelock H, Gaisford P, Calin A. A new approach to defining disease status in ankylosing spondylitis: the Bath Ankylosing Spondylitis Disease Activity Index. J Rheumatol 1994;21:2286-91.

6. Lukas C, Landewé R, Sieper J, Dougados M, Davis J, Braun J, et al; Assessment of SpondyloArthritis international Society.

Development of an ASAS-endorsed disease activity score (ASDAS) in patients with ankylosing spondylitis. Ann Rheum Dis 2009;68:18-24

7. van der Heijde D, Lie E, Kvien TK, Sieper J, Van den Bosch F, Listing J, et al; Assessment of SpondyloArthritis international Society (ASAS). ASDAS, a highly discriminatory ASAS-endorsed disease activity score in patients with ankylosing spondylitis. Ann Rheum Dis 2009;68:1811-8.

8. Calin A, Garrett S, Whitelock H, Kennedy LG, O'Hea J, Mallorie P, et al. A new approach to defining functional ability in ankylosing spondylitis: the development of the Bath Ankylosing Spondylitis Functional Index. J Rheumatol 1994;21:2281-5.

9. van der Linden S, Valkenburg HA, Cats A. Evaluation of diagnostic criteria for ankylosing spondylitis. A proposal for modification of the New York criteria. Arthritis Rheum 1984;27:361-8.

10. Rudwaleit M, van der Heijde D, Landewé R, Akkoc N, Brandt J, Chou CT, et al. The Assessment of SpondyloArthritis International Society classification criteria for peripheral spondyloarthritis and for spondyloarthritis in general. Ann Rheum Dis 2011;70:25-31.

11. Taylor W, Gladman D, Helliwell P, Marchesoni A, Mease P, Mielants H, et al; CASPAR Study Group. Classification criteria for psoriatic arthritis: development of new criteria from a large international study. Arthritis Rheum 2006;54:2665-73.

12. Yoshida K, Bohn J. Package "tableone" [Internet. Accessed December 20, 2018.] Available from: https://CRAN.R-project.org/ package $=$ tableone

13. Chen H, Boutros PC. VennDiagram: a package for the generation of highly-customizable Venn and Euler diagrams in R. BMC Bioinformatics 2011;12:35.

14. Bakker P, Moltó A, Etcheto A, Van den Bosch F, Landewé R, van Gaalen F, et al. The performance of different classification criteria sets for spondyloarthritis in the worldwide ASAS-COMOSPA study. Arthritis Res Ther 2017;19:96.

15. Reveille JD, Hirsch R, Dillon CF, Carroll MD, Weisman MH. The prevalence of HLA-B27 in the US: data from the US National Health and Nutrition Examination Survey, 2009. Arthritis Rheum 2012;64:1407-11.

16. Arnbak B, Grethe Jurik A, Hørslev-Petersen K, Hendricks O, Hermansen LT, Loft AG, et al. Associations between spondyloarthritis features and magnetic resonance imaging findings: a cross-sectional analysis of 1,020 patients with persistent low back pain. Arthritis Rheumatol 2016;68:892-900.

17. Xiang YJ, Dai SM. Prevalence of rheumatic diseases and disability in China. Rheumatol Int 2009;29:481-90.

18. Liao ZT, Pan YF, Huang JL, Huang F, Chi WJ, Zhang KX, et al. An epidemiological survey of low back pain and axial spondyloarthritis in a Chinese Han population. Scand J Rheumatol 2009;38:455-9. 
19. Tam LS, Tomlinson B, Chu TT, Li M, Leung YY, Kwok LW, et al. Cardiovascular risk profile of patients with psoriatic arthritis compared to controls - the role of inflammation. Rheumatology 2008;47:718-23.

20. Tsai YG, Chang DM, Kuo SY, Wang WM, Chen YC, Lai JH. Relationship between human lymphocyte antigen-B27 and clinical features of psoriatic arthritis. J Microbiol Immunol Infect 2003;36:101-4.

21. Thumboo J, Tham SN, Tay YK, Chee T, Mow B, Chia HP, et al. Patterns of psoriatic arthritis in Orientals. J Rheumatol 1997;24:1949-53.

22. Fan X, Yang S, Sun LD, Liang YH, Gao M, Zhang KY, et al. Comparison of clinical features of HLA-Cw*0602-positive and -negative psoriasis patients in a Han Chinese population. Acta Derm Venereol 2007;87:335-40

23. Baek HJ, Yoo CD, Shin KC, Lee YJ, Kang SW, Lee EB, et al. Spondylitis is the most common pattern of psoriatic arthritis in Korea. Rheumatol Int 2000;19:89-94.

24. Ohara Y, Kishimoto M, Takizawa N, Yoshida K, Okada M, Eto H, et al. Prevalence and clinical characteristics of psoriatic arthritis in Japan. J Rheumatol 2015;42:1439-42.

25. Yamamoto T, Ohtsuki M, Sano S, Igarashi A, Morita A, Okuyama $\mathrm{R}$, et al; Working Group of the Epidemiological Survey in the Japanese Society for Psoriasis Research. Prevalence and current therapies of psoriatic arthritis in Japan: a survey by the Japanese Society of Psoriasis Research in 2016. J Dermatol 2017;44:e121. 